\title{
A OBRA O MERCADOR DE VENEZA: PROBLEMATIZAÇÃO E DISCURSO NO ENSINO MÉDIO
}

\author{
Noemi Sutil \\ Igo Levir Souza Rabelo ${ }^{* *}$ \\ Louise Sarris Schmitz ${ }^{* * *}$
}

Resumo: Neste trabalho são analisados processos de problematização e discurso em proposta educacional, com base em estudos de relações entre Ciência, Tecnologia, Sociedade e Ambiente (CTSA) e Arte, a partir de abordagem da obra O Mercador de Veneza, de William Shakespeare. Essas ações envolveram estudantes de $3^{\circ}$ ano de Ensino Médio, em Curitiba, Paraná, 2016. Nessa proposta, destaca-se a articulação entre Física, Matemática, Língua Portuguesa e Língua Inglesa, no contexto do Programa Institucional de Bolsa de Iniciação à Docência (PIBID), modalidade interdisciplinar. Este trabalho agrega proposições de Jürgen Habermas e Paulo Freire no que concerne aos conceitos de formação, problematização e discurso, em referência aos âmbitos: explicativo, objetivo, social e subjetivo. No que concerne ao âmbito explicativo foram explicitadas proposições de David Ausubel e colaboradores sobre aprendizagem significativa. Os dados foram constituídos por meio de: gravações em áudio e vídeo; trabalhos elaborados pelos alunos. Esses dados foram analisados conforme Análise de Conteúdo. Entre os resultados, podem ser destacados: envolvimento em problematização e proposições; interações discursivas relacionadas a âmbitos formativos.

Palavras-chave: Formação. Problematização. Discurso.

\section{Introdução}

Educação demanda o questionamento do conceito de formação. Esse conceito pode ser associado à convivência e colaboração entre sujeitos diferentes. Nessa concepção de educação e formação adquirem destaque os processos de problematização e construções conjuntas, agregando interações discursivas, que podem ser compreendidos conforme pressupostos das teorias da Ação Dialógica (FREIRE, 2005), do Agir Comunicativo (HABERMAS, 2002, 2012a, 2012b) e da Aprendizagem Significativa (AUSUBEL et al., 1980).

No escopo de fundamentos teóricos dessas teorias, neste trabalho, são apresentadas considerações sobre processos de problematização e discurso em proposta educacional, abrangendo a obra $O$ Mercador de Veneza de William Shakespeare, e relações entre Ciência,

\footnotetext{
* Universidade Tecnológica Federal do Paraná (UTFPR), Departamento Acadêmico de Física (DAFIS). Doutora em Educação para a Ciência.

${ }^{* *}$ Universidade Tecnológica Federal do Paraná (UTFPR). Estudante de Curso de Licenciatura em Física.

${ }^{* * *}$ Universidade Tecnológica Federal do Paraná (UTFPR). Estudante de Curso de Licenciatura em Letras.
} 
Tecnologia, Sociedade e Ambiente (CTSA) e Arte. Essa proposta foi desenvolvida em perspectiva de pesquisa-ação, envolvendo estudantes e docentes da Educação Básica e de Ensino Superior e as áreas de Física, Matemática, Língua Portuguesa e Língua Inglesa. Nesse cenário, as interações discursivas são evidenciadas em referência a domínios formativos.

\section{2 Âmbitos formativos, problematização e discurso}

Formação, em perspectiva habermasiana, relaciona-se com o entendimento entre sujeitos em processos argumentativos e livres de coerção. Entendimento remete à formação em quatro âmbitos formativos distintos: explicativo, objetivo, social e subjetivo. (HABERMAS, 2012a, 2012b)

O âmbito explicativo abrange o panorama linguístico e conceitual que viabiliza as interações comunicativas (HABERMAS, 2002). Nesse âmbito, podem ser relacionadas as proposições de David Ausubel e colaboradores sobre aprendizagem significativa, particularmente em referência às modalidades representacional, proposicional e conceitual (AUSUBEL et al., 1980).

Aprendizagem significativa implica o estabelecimento de relações entre conhecimentos já apropriados pelo sujeito e novos conteúdos a serem aprendidos. Nessa perspectiva, a aprendizagem representacional se associa à incorporação de elementos linguísticos de representação. A aprendizagem proposicional compreende a utilização de códigos linguísticos em sentenças gramaticais. A aprendizagem conceitual agrega a apropriação de conceitos, com processos de formação e assimilação. (AUSUBEL et al., 1980)

Formação de conceitos envolve a elaboração, análise de hipóteses e composição de modelo explicativo por parte do aprendiz, com base nos exemplares observados e ênfase no domínio empírico-concreto. Esses procedimentos podem ser associados à aprendizagem por descoberta. A assimilação de conceitos pode ser relacionada à aprendizagem por recepção, com a apropriação de construções teóricas estabilizadas em processos específicos, como ocorre no contexto da ciência. Dessa forma, essa aprendizagem conceitual pode abranger relações: entre conceitos e aspectos contextuais, em referência ao domínio empírico-concreto; entre conceitos, compreendendo construções teóricas estabilizadas. Nesse sentido, destaca-se que, em algumas situações, o sujeito pode reconhecer uma representação sem a apreensão do conceito ou reconhecer o conceito e não a sua representação. (AUSUBEL et al., 1980)

O âmbito objetivo se refere a conhecimentos estabilizados, concepções e saberes. Relaciona-se com a natureza externa, com proposições de observador sobre como as coisas 
são no mundo (HABERMAS, 2002). Agrega, também, aspectos epistemológicos relacionados à construção e estabilização de conhecimentos científicos.

O âmbito social remete à interação entre sujeitos, compreendendo normas e direitos (HABERMAS, 2002). Envolve, também, aspectos relacionados à utilização de conhecimentos científicos e tecnologias.

O âmbito subjetivo concerne à natureza interna, aos sentimentos e padrões valorativos (HABERMAS, 2002). Perpassa, também, as intenções dos sujeitos participantes em relação aos processos de problematização e construções conjuntas, para que tais situações representem argumentação livre de coerção e de manipulação.

Problematização e construções conjuntas nesses âmbitos formativos remetem ao estabelecimento de discurso/crítica. Ao âmbito explicativo, relaciona-se o discurso explicativo. No âmbito objetivo, há expressão de discurso objetivo. O âmbito social agrega o discurso prático. O âmbito subjetivo, diferenciado em termos de processos idiossincráticos, envolve crítica terapêutica e estética. Na crítica terapêutica, há análise de percepções e de atitudes. Na crítica estética, há questionamento de padrões estéticos e valorativos, vinculados a aspectos subjetivos de constituição de relações entre sujeitos e destes com suas produções e elementos dos contextos vivenciais. (HABERMAS, 2002)

Formação e educação, nessa perspectiva, demandam o desenvolvimento de atividades educativas com a viabilização de processos discursivos, com a problematização de aspectos da realidade vivencial e proposições direcionadas a construções conjuntas, seja em termos de significados e estruturas linguísticas (âmbito explicativo), conhecimentos estabilizados, concepções e saberes (âmbito objetivo), normas e direitos (âmbito social) ou percepções, atitudes e padrões valorativos (âmbito subjetivo).

Essas metas podem ser associadas a pressupostos de estudos envolvendo as relações

entre Ciência, Tecnologia, Sociedade e Ambiente (CTSA), em que se defende o desenvolvimento de atividades educacionais que proporcionem questionamento e proposições de alternativas por parte dos discentes no que concerne a situações controversas de seus contextos (ZOLLER, 1992; MARTÍNEZ, 2012).

\section{A obra $O$ Mercador de Veneza}

A obra $O$ Mercador de Veneza remete ao contexto da cidade de Veneza, século XIV. Essa produção literária destaca a problemática envolvendo o pagamento de uma dívida de Antônio, proprietário de navios, ao judeu Shylock. Essa situação se estabelece porque Bassânio pretende cortejar a rica herdeira Pórcia e, por isso, solicita empréstimo de três mil 


\section{\#tear}

ducados ao seu amigo Antônio. Sem poder dispor dessa quantia, Antônio, por sua vez, solicita empréstimo a Shylock. Este empresta o valor, impondo a condição de que, em caso de não pagamento no prazo estabelecido, Antônio deverá fornecer uma libra de sua própria carne. Bassânio consegue ir a Belmonte e se casa com Pórcia. Antônio, contudo, recebe a notícia do naufrágio de seus navios e não consegue pagar a dívida. (SHAKESPEARE, 2007)

Nesse contexto, Shylock exige o pagamento da dívida por meio da retirada de uma libra da carne de Antônio. Mesmo com a disponibilização de valor acima da quantia do empréstimo, Shylock faz questão do cumprimento do contrato, considerando a extrapolação do prazo estabelecido. Pórcia se disfarça em trajes masculinos, a fim de poder exercer papel de advogado, exclusivo aos homens na época, e assume função jurídica no julgamento da situação. Na impossibilidade de retirada do pedaço de carne sem derramamento de sangue, que poderia causar a morte do acusado, ela evoca legislação sobre atentado à vida. Com esse estratagema, livra o acusado do cumprimento da punição, e viabiliza a definição de que metade dos bens de Shylock deverá ser repassada a Antônio. (SHAKESPEARE, 2007)

\section{Procedimentos metodológicos}

Este trabalho envolve pesquisa-ação (CARR \& KEMMIS, 2004), com atividades educacionais desenvolvidas em Curitiba, Paraná, em 2016, envolvendo: estudantes universitários em formação inicial de cursos de licenciatura; estudantes e professores da rede estadual de Educação Básica; professor universitário orientador. O processo envolveu as áreas de Física, Matemática, Língua Portuguesa e Língua Inglesa, no contexto do Programa Institucional de Bolsa de Iniciação à Docência (PIBID), modalidade interdisciplinar. Os dados foram constituídos por meio de gravações em áudio e vídeo e trabalhos elaborados por alunos da Educação Básica.

Essas atividades educacionais foram desenvolvidas em seis horas-aula com 20 alunos de $3^{\circ}$ ano de Ensino Médio (conjuntos de atividades 1 e 2). No Quadro 1 são apresentadas características gerais dessas atividades educacionais. 
Quadro 1. Características gerais de atividades educacionais.

\begin{tabular}{|l|l|}
\hline \multicolumn{1}{|c|}{ PROCEDIMENTOS } & \multicolumn{1}{c|}{ OBJETIVOS } \\
\hline 1. Questionamentos sobre o autor e a obra. & $\begin{array}{l}\text { Verificação de conhecimentos prévios e expressões } \\
\text { subjetivas sobre o autor e a obra. }\end{array}$ \\
\cline { 1 - 2 } 2. Análise de características do autor e da obra. & $\begin{array}{l}\text { Reconhecimento e problematização de padrões } \\
\text { valorativos. }\end{array}$ \\
\cline { 1 - 2 } $\begin{array}{l}\text { 3. Análise de contexto científico, tecnológico, } \\
\text { social, ambiental e artístico da obra. }\end{array}$ & $\begin{array}{l}\text { Reconhecimento e problematização de relações CTSA } \\
\text { e Arte. }\end{array}$ \\
\cline { 1 - 2 } $\begin{array}{l}\text { 4. Análise de contexto científico, tecnológico, } \\
\text { social, ambiental e artístico contemporâneo. }\end{array}$ & \\
\hline
\end{tabular}

Fonte: Autores.

Apresenta-se, a seguir, o detalhamento das atividades educacionais desenvolvidas.

\subsection{Conjunto de atividades 1}

Inicialmente, houve explicitação de características gerais do autor e principais obras, com verificação de conhecimentos prévios. Nessa situação, foi possível constatar pouco conhecimento dos discentes sobre o autor William Shakespeare e suas obras. Partindo desses conhecimentos prévios, foi encaminhada explanação sobre a importância do autor e de suas obras nos contextos literário e social.

A seguir, foi realizada a apresentação de texto jornalístico sobre conflitos envolvendo inadimplência, para posterior associação com situação abordada na obra literária. Nesse momento, os alunos dialogaram sobre problemas enfrentados em virtude desse motivo.

Logo após, foram explicitadas características mais específicas sobre o estilo, a escrita e escolhas temáticas de William Shakespeare e suas obras. Houve destaque da singularidade dessas obras, do caráter crítico em relação à sociedade, das figuras de linguagem mais recorrentes e do período histórico do autor. Foi evidenciada, também, homenagem aos 400 anos de sua morte, em 2016.

A seguir, foi realizada a apresentação e problematização da obra $O$ Mercador de Veneza. Entre os questionamentos abordados, podem ser destacados: Por que esta obra e não outra? Quando foi escrita? Qual o seu objetivo? Por que discutir ela hoje?

Houve, também, a discussão dos principais temas abordados na obra, tais como: religião, antissemitismo, aspectos jurídicos e econômicos. Foram explicitados: enredo, personagens, contexto. Nesse momento, foi possível questionar a atualidade desses temas e os alunos relacionaram aspectos contextuais da obra a situações contemporâneas. Ao final desse conjunto de atividades, os discentes elaboraram um texto expondo análises sobre a obra, em alusão a contextos literário e contemporâneo. 


\subsection{Conjunto de atividades 2}

Nesse conjunto de atividades, inicialmente, houve prosseguimento da apresentação da história em questão. O foco principal da aula era fazer uma análise jurídica do problema que aparece na obra. Para que esse transtorno fosse analisado foi necessário levar em consideração o contexto, os personagens e suas particularidades, o problema entre eles, o desenvolvimento e o desfecho da situação.

A seguir, foi realizado debate pelos discentes envolvendo os aspectos jurídicos da obra. Os alunos foram divididos em dois grupos, um com a defesa de Antônio e outro de Shylock. Eles elaboraram argumentos, dialogando a respeito da obra.

A dinâmica era que um grupo, inicialmente, defendesse um dos dois personagens. Após isso acontecer, eles deveriam trocar de personagem a ser defendido. Ou seja, eles tinham que contrapor seus próprios argumentos. Houve intensa participação dos alunos.

\section{Análise de dados}

Os dados foram analisados por meio de Análise de Conteúdo (BARDIN, 2011). Os alunos da Educação Básica são identificados pela letra A seguida de número (exemplo: A1) e os estudantes universitários pela letra P seguida de número (exemplo: P1). A letra T se refere a turno em um conjunto de expressões e TE remete a texto escrito. As unidades de contexto para análise foram selecionadas considerando os âmbitos formativos da Teoria do Agir Comunicativo, conforme exposto no Quadro 2.

Quadro 2. Orientações de seleção de unidades de contexto.

\begin{tabular}{|l|l|}
\hline \multicolumn{1}{|c|}{ ÂMBITOS } & \multicolumn{1}{c|}{ OBJETIVOS } \\
\hline Objetivo & $\begin{array}{l}\text { Expressões envolvendo problematização e proposições sobre conhecimentos } \\
\text { estabilizados, concepções e saberes. }\end{array}$ \\
\hline Social & Expressões envolvendo problematização e proposições sobre normas e direitos. \\
\hline Subjetivo & $\begin{array}{l}\text { Expressões envolvendo problematização e proposições sobre percepções, atitudes e } \\
\text { padrões valorativos. }\end{array}$ \\
\hline Explicativo & $\begin{array}{l}\text { Expressões envolvendo problematização e proposições sobre significados e estruturas } \\
\text { linguísticas. }\end{array}$ \\
\hline
\end{tabular}

Fonte: Autores.

A análise de dados envolve dois eixos: envolvimento em problematização e discurso; alusão a âmbitos formativos em processos de problematização e discurso. Neste trabalho, as considerações são explicitadas com apresentação de exemplares de expressões em: texto 
escrito (Conjunto de atividades 1); debate (Conjunto de atividades 2); participações em sala de aula (Conjunto de atividades 2).

\subsection{Expressões em texto escrito}

$\mathrm{Na}$ apresentação das expressões, os textos foram mantidos como originalmente escritos, sem correções de Língua Portuguesa. No Quadro 3 são apresentados exemplares relacionados às expressões dos alunos da Educação Básica concernentes ao âmbito objetivo, em que se ressalta a análise de conflitos religiosos.

Quadro 3. Exemplares de Expressões. Âmbito Objetivo.

\begin{tabular}{|l|l|}
\hline \multicolumn{1}{|c|}{ UNIDADE DE CONTEXTO } & \multicolumn{1}{c|}{ COMENTÁRIOS } \\
\hline $\begin{array}{l}\text { TE2: É uma obra extremamente profunda. Indica as diferenças } \\
\text { entre ser cristão e judeu, os defeitos e qualidades dos dois. }\end{array}$ & Conflitos Religiosos. \\
\hline $\begin{array}{l}\text { TE6: Em questão das torturas de religião, hoje em dia } \\
\text { continua mais é um pouco mais reservado. Acontece muita } \\
\text { desigualdade. }\end{array}$ & \\
\hline
\end{tabular}

Fonte: Autores.

Destacam-se, dessa forma, expressões dos estudantes em relação ao âmbito objetivo, particularmente, na proposição de interpretações relacionadas à obra e ao contexto contemporâneo, com o estabelecimento de relações entre momentos históricos específicos.

No Quadro 4 são apresentados exemplares relacionados às expressões dos alunos da Educação Básica concernentes ao âmbito social.

Quadro 4. Exemplares de Expressões. Âmbito Social.

\begin{tabular}{|c|c|}
\hline UNIDADE DE CONTEXTO & COMENTÁRIOS \\
\hline $\begin{array}{l}\text { TE1: A obra mostra }[\ldots] \text { a intolerância religiosa, a falha da } \\
\text { justiça. Pessoas de grande importância e de classe alta } \\
\text { conseguindo influenciar a imparcialidade do juiz. A injustiça } \\
\text { que se tornou justiça pela influência da maioria sobre a } \\
\text { minoria. }\end{array}$ & $\begin{array}{l}\text { Injustiça Social. Explicação por meio do } \\
\text { reconhecimento da ruptura com a noção } \\
\text { coletiva de justiça. }\end{array}$ \\
\hline $\begin{array}{l}\text { TE7: A justiça não pode ter gênero, raça, religião ou qualquer } \\
\text { meio que leve uma pessoa ou um grupo a levar vantagens, } \\
\text { porém a intolerância e o preconceito são temas que ainda } \\
\text { pesam na justiça. }\end{array}$ & $\begin{array}{l}\text { Injustiça Social. Explicação por meio da } \\
\text { noção coletiva de justiça. }\end{array}$ \\
\hline $\begin{array}{l}\text { TE8: Acontece diariamente nos dois dias de hoje em } \\
\text { julgamentos, havendo desigualdade nos decretos. }\end{array}$ & $\begin{array}{l}\text { Injustiça Social. Reconhecimento de } \\
\text { aspectos contemporâneos tendo em vista a }\end{array}$ \\
\hline
\end{tabular}




\begin{tabular}{|l|l|}
\hline & noção coletiva de justiça. \\
\hline $\begin{array}{l}\text { TE7: A mulher para ser importante deveria ser um “homem” } \\
\text { antigamente e isso ocorre até hoje no machismo. Sociedade } \\
\text { alienada com vestígios do passado em relação à discriminação } \\
\text { de crenças. }\end{array}$ & $\begin{array}{l}\text { Papel Social da Mulher. Reconhecimento de } \\
\text { desigualdades. }\end{array}$ \\
\hline $\begin{array}{l}\text { TE11: As mulheres ainda continuam sem voz, pois desde anos } \\
\text { atrás continua sendo atual. }\end{array}$ & $\begin{array}{l}\text { Papel Social da Mulher. Reconhecimento de } \\
\text { desigualdades. }\end{array}$ \\
\hline
\end{tabular}

Fonte: Autores.

No que concerne ao âmbito social, as expressões dos discentes permearam a análise de processos de estabelecimento de regulamentações e suas implicações sociais. Destacaram aspectos morais relacionados à convivência entre sujeitos. Por outro lado, questionaram convenções sociais associadas às regulamentações, particularmente, o papel social da mulher.

No Quadro 5 são apresentados exemplares relacionados às expressões dos alunos da Educação Básica concernentes ao âmbito subjetivo.

Quadro 5. Exemplares de Expressões. Âmbito Subjetivo.

\begin{tabular}{|c|c|}
\hline UNIDADE DE CONTEXTO & COMENTÁRIOS \\
\hline $\begin{array}{l}\text { TE1: A obra mostra que nos dias de hoje vivenciamos os } \\
\text { mesmos conflitos internos (a mudança de sentimentos por } \\
\text { conta de algumas situações). }\end{array}$ & $\begin{array}{l}\text { Reflexões Geradas. Estreitamento de laços } \\
\text { entre obra e leitor. }\end{array}$ \\
\hline $\begin{array}{l}\text { TE2: A obra gera discussões com argumentos que possuem } \\
\text { muito fundamento [...]. Faz as pessoas refletirem. }\end{array}$ & Reflexões Geradas. Postura reflexiva. \\
\hline $\begin{array}{l}\text { TE5: A obra causou um impacto de reflexão e pensamento de } \\
\text { quem foi o errado e certo na história. Devemos sempre ver os } \\
\text { dois lados e se pôr no lugar dos personagens. }\end{array}$ & $\begin{array}{l}\text { Reflexões Geradas. Recepção da Obra. } \\
\text { Empatia direcionada a situações vivenciadas } \\
\text { por personagens. }\end{array}$ \\
\hline
\end{tabular}

Fonte: Autores.

Em relação ao âmbito subjetivo, os discentes destacaram experiências pessoais viabilizadas pela análise da obra. Nos exemplares explicitados, destaca-se o desenvolvimento de postura reflexiva.

No Quadro 6 são apresentados exemplares relacionados às expressões dos alunos da Educação Básica concernentes ao âmbito explicativo. As alusões a esse âmbito envolvem apenas o reconhecimento do mesmo para a construção de panorama linguístico e conceitual, devido à característica dessa modalidade de dados. 
Quadro 6. Exemplares de Expressões. Âmbito Explicativo.

\begin{tabular}{|l|l|}
\hline \multicolumn{1}{|c|}{ UNIDADE DE CONTEXTO } & \multicolumn{1}{c|}{ COMENTÁRIOS } \\
\hline $\begin{array}{l}\text { TE9: A literatura está muito desvalorizada, com isso alguns } \\
\text { temas destrói o interesse da leitura. O tema é necessário na } \\
\text { leitura, é ele que faz com que as pessoas sintam vontade de } \\
\text { continuar lendo seu livro, revista até mesmo jornal. }\end{array}$ & Leitura e Educação. Experiência literária. \\
\hline $\begin{array}{l}\text { TE6: A obra foi para que nós de hoje em dia saiba intender as } \\
\text { coisas sabendo o "porque". }\end{array}$ & $\begin{array}{l}\text { Leitura e Educação. Entendimento da } \\
\text { produção literária como meio de ampliação } \\
\text { de panorama linguístico e conceitual. }\end{array}$ \\
\hline
\end{tabular}

Fonte: Autores.

As atividades educacionais desenvolvidas foram relacionadas a um processo formativo mais amplo, que extrapola a mera abordagem do âmbito explicativo. Envolveram uma proposta de articulação entre áreas de conhecimento.

\subsection{Expressões em debate}

No debate realizado no Conjunto de atividades 2 são destacadas expressões dos estudantes (turnos T1 a T16), referentes à defesa de Shylock e Antônio.

T1. A1: Então, cada um é livre com suas escolhas, cada um pode fazer o que quiser fazer. O primeiro foi o Antonio aceitou fazer um contrato com Shylock, ele sabia das condições, ele sabia das consequiências e aceitou fazer o contrato mesmo sabendo que ele tinha que pagar o valor dentro de três meses. Passou três meses, ele quis pagar o dobro, só que Shylock não aceitou porque o acordo foi três meses para ser pago o valor e a gente defende o Shylock porque o Antonio sabia muito bem das consequiências que ele ia sofrer. Então a gente concorda que o Shylock deva tirar 1 quilo de carne do Antonio, mesmo sabendo que primeiro vem o direito da vida. Mas o Antônio sabia muito bem que passado três meses se ele não pagar, ia ser tirado 1quilo de carne dele. [...]

T2. A3: Então, a gente defende o Antonio porque ele tentou cumprir o contrato e ele tentou pagar o valor, mas ele não conseguiu devido a uma catástrofe natural, que o navio dele sumiu ou foi saqueado pelos piratas. E segundo que em algum momento o contrato diz que o Antonio tem que estar vivo para esse 1 quilo de carne? Porque senão Shylock pode pegar esse 1 quilo de carne depois que o Shylock morrer e aí ele vai coletar sua dívida. (Risos) [...]

T3. A4: Tipo... estava escrito lá que era os três meses para ele pagar, só que tipo, mesmo falando isso, não falava que ele precisava estar vivo para ele tirar a carne.

T4. A5: Não estipulava uma data

T5. A4: Estipulava na verdade, estipulava para ele pagar, mas não para dar 1 quilo de carne.

T6. A3: Mas o contrato ele fez quando ele estava vivo ou estava morto?

T7. A4: Quando ele estava vivo, mas o contrato não diz que ele precisa estar vivo e outra que ele tentou pagar o dobro.

T8. A3: Mas ele tentou depois dos três meses. 


\section{\#tear}

T9. A4: Mas não, já é três meses... teria que ser três meses.. mas ele tentou pagar o dobro e mesmo assim... [...]

T10. P2: Eu acho que ela argumentou bem porque assim, o contrato só previa o pagamento em dinheiro, os três meses. O quilo de carne poderia ser pago depois. [...] T11. A3: É, ele tinha o direito de não assinar se ele não quisesse, mas ele assinou. (Risos) $[\ldots]$

T12. P2: Ok pessoal, então... agora vocês vão defender Shylock e vocês o Antonio. [Há troca de partes em defesa entre os grupos] [...]

T13. A2: A gente defende Shylock porque primeiro lá em Veneza tinha aquele negócio de cumprir contrato, não só em Veneza, mas o que estava assinado tinha que ser feito. Todo mundo sabe as consequências de um contrato, até no trabalho e assina qualquer coisa, a gente tem que cumprir aquilo, é lei. E ele não cumpriu. Mesmo se ele tivesse pagado no último dia até meia noite seria justo, mas ele não conseguiu e foi julgado depois do prazo, então não tem o que ele fazer, ele sabia que teria que entregar um 1 quilo de carne mesmo que o cara não conseguisse pesar 1 quilo de carne e se não pudesse sangrar e mesmo assim ele sabia que mexeria com a vida dele. (Aplausos)

T14. A4: Quem que eu defendo mesmo? (Risos) Ele tem a liberdade total de colocar tudo que ele quiser no contrato, mas daí o contratante ele quer aceitar tudo isso, porém o contrato tem que ser totalmente formal e afetivo, e ele deixou espaço para brechas para interpretação diversas e isso não pode no contrato. Aí o outro lado achou essas brechas e é o que acontece muito hoje em dia, os contratos eles são alterados por causa disso. [...]

T15. P2: Calma que ele tem dois advogados.

T16. A5: E além de que Antonio, a gente defende Antonio porque Shylock fez esse contrato de uma forma vingativa de se vingar de Antonio e realmente o contrato tem que ser seguido só que tem que considerar os direitos humanos, é desumano você tirar 1 quilo de carne de uma pessoa.

No Quadro 7 são destacadas algumas alusões a âmbitos formativos considerando as expressões explicitadas concernentes ao debate entre os discentes.

Quadro 7. Alusões a âmbitos formativos.

\begin{tabular}{|c|c|c|c|}
\hline ITEM & TURNO & $\begin{array}{c}\text { ASPECTOS EM } \\
\text { PROBLEMATIZAÇÃO/DISCURSO }\end{array}$ & $\begin{array}{c}\text { ÂMBITO } \\
\text { DESTACADO }\end{array}$ \\
\hline 1 & $\begin{array}{c}\text { T1/T2 } \\
\text { T7/T8/T9 } \\
\text { T10 }\end{array}$ & Condições de validade de acordo. & SOCIAL \\
\hline 2 & $\begin{array}{c}\text { T3/T4/T5/T6/T7 } \\
\text { T14 }\end{array}$ & $\begin{array}{l}\text { Interpretação de situação relacionada ao cumprimento } \\
\text { do acordo. }\end{array}$ & OBJETIVO \\
\hline 3 & T16 & Concepções sobre humanidade. & SUBJETIVO \\
\hline
\end{tabular}

Fonte: Autores.

Nesse trecho do debate, os alunos ressaltaram as condições de validade de acordos, em referência ao âmbito social, de regulação de interações entre sujeitos. As alusões ao âmbito objetivo se referiram ao conteúdo do acordo, sua interpretação. Em âmbito subjetivo, houve explicitação de concepções sobre a vida humana e os direitos relacionados a ela. 
5.3 Expressões em participações em sala de aula

No Conjunto de atividades 2 são destacadas expressões em dois episódios (1 e 2). No Episódio 1 (turnos T1 a T7), apresentado a seguir, ressalta-se a alusão a âmbito subjetivo, vinculando situações cotidianas e a obra.

T1. P1: É... aqui eu estou falando do humanismo, porque como eu disse o Shakespeare explorava essas questões controversas do ser humano, esses pares de coisas opostas. É... como que está para vocês, vocês entendem o que seriam esses pares de coisas opostas? Por que vocês acham que a gente pode afirmar que o ser humano é uma coisa controversa? [...]

T2. A6: Eu acho que... acho que no dia-a-dia a gente já percebe isso. A gente acorda bem ou a gente acorda super feliz e sei lá acontece alguma coisa que a gente já vai se entristecendo, vai ficando com raiva. E no dia a gente percebe como a gente é o oposto, como a gente ama e odeia ao mesmo tempo... [Diálogo não compreendido, risos]. É impressionante isso.

T3. A6: [Diálogo não compreendido] ... com relacionamento, a gente está brigando, mas a gente não quer brigar porque a gente ama ela.

T5. P2: Ou acontece o inverso, você tem lá o teu melhor amigo, por exemplo, da escola e tal, mas ele é o teu melhor amigo até o dia que ele não te contraria.

T6. A6: É exatamente...

T7. P2: No dia que ele for contrário a uma ideia tua você já fica meio assim "poxa, mas esse cara aí está me contrariando", não está de acordo com o que a gente pensa, com o que a gente crê, então é mais um exemplo aí.

No Episódio 2 (turnos T1 e T2), a seguir, destaca-se a análise proposta pela aluna A7 sobre os aspectos jurídicos presentes na obra, em alusão ao âmbito social.

T1. A7: Eu acho que nessa obra de Shakespeare ele quis mostrar uma história para a gente parar de ser manipulado e refletir no que a gente está fazendo.

T2. P1: E é interessante só de sacar isso que você falou. Por que no final a gente tem essa impressão, igual ele falou, de que o judeu é mesmo o vilão e o Antonio o mocinho da história? [...] Isso o que você disse da gente fazer as coisas sem saber o porquê, a gente só seguiu o coletivo.

Nas participações dos discentes em sala de aula, houve alusão ao âmbito social em diversos momentos. Essa referência ao âmbito social demandou a articulação com os âmbitos objetivo e subjetivo.

Nos dois conjuntos de atividades, destaca-se o processo argumentativo entre os discentes e a disposição dos estudantes para envolvimento em problematização e discurso.

\section{Considerações finais}

No decorrer da análise da obra, houve necessidade de ampliação do âmbito explicativo, com a abordagem de conteúdos de diversas áreas de conhecimento, 


\title{
\#tear
}

particularmente Física, Matemática, Língua Portuguesa e Língua Inglesa. Entretanto, a abordagem do âmbito explicativo esteve situada na problematização dos outros três âmbitos (objetivo, social e subjetivo). Isso representa possibilidades para a atribuição de sentidos e significados à abordagem de conteúdos escolares. Nessa perspectiva, a abordagem de relações CTSA e Arte constitui alternativa em uma concepção de formação que envolve a apropriação de conteúdos escolares e a problematização de aspectos de construção e utilização de conhecimentos científicos, tecnologias e produções artísticas.

Agradecimentos à Coordenação de Aperfeiçoamento de Pessoal de Nível Superior (CAPES) pelo apoio financeiro.

\section{THE WORK "THE MERCHANT OF VENICE": PROBLEM-POSING AND DISCOURSE IN HIGH SCHOOL}

\begin{abstract}
The present work consists in the analysis of process of problem-posing and discourse concerning educational proposal, which was based on studies of relations among Science, Technology, Society and Environment (STSE) and Art, through the approach of the work "The Merchant of Venice", by William Shakespeare. These actions involved students of 3rd year of High School, in Curitiba, Paraná, 2016. The contents of the subjects of Physics, Mathematics, Portuguese and English were articulated in this educational proposal, which was elaborated in the context of the Institutional Program of Initiation to Teaching Scholarship (PIBID), interdisciplinary modality. This work has its fundaments on the theories of Jürgen Habermas and Paulo Freire concerning to the concepts of formation, problem-posing and discourse, in reference to the formative domains: explicative, objective, social and subjective. Regarding the explicative domain, the propositions of David Ausubel and collaborators on meaningful learning were highlighted. Data were defined by means of audio and video records and written works, carried out by the students. Among the results, it is possible to highlight: involvement in problem-posing and propositions; discursive interactions related to formative domains.
\end{abstract}

Keywords: Formation. Problem-posing. Discourse.

\section{Referências}

AUSUBEL, D. P.; NOVAK, J. D.; HANESIAN, H. Psicologia educacional. Rio de Janeiro: Interamericana, 1980.

BARDIN, L. Análise de conteúdo. São Paulo: Edições 70, 2011.

CARR, W.; KEMMIS, S. Becoming critical: education, knowledge and action research. New York: Taylor \& Francis e-Library, 2004. 
FREIRE, P. Pedagogia do oprimido. Rio de Janeiro: Paz e Terra, 2005.

HABERMAS, J. Racionalidade e comunicação. Lisboa: Edições 70, 2002.

HABERMAS, J. Teoria do agir comunicativo I: racionalidade da ação e racionalização social. São Paulo: WMF Martins Fontes, 2012a.

HABERMAS, J. Teoria do agir comunicativo II: sobre a crítica da razão funcionalista. São Paulo: WMF Martins Fontes, 2012b.

MARTÍNEZ, L. F. P. Questões sociocientíficas na prática docente: Ideologia, autonomia e formação de professores. São Paulo: Editora UNESP, 2012.

SHAKESPEARE, W. O mercador de Veneza. Porto Alegre: L\&PM, 2007.

ZOLLER, U. The Technology/Education Interface: STES Education for All. Canadian Journal of Education, v. 17, n. 1, p. 86-91, 1992. 